\title{
The genotypes of GYPA and GYPB carrying the MNSs antigens are not associated with cerebral malaria
}

\author{
Izumi Naka $\cdot$ Jun Ohashi $\cdot$ Jintana Patarapotikul · \\ Hathairad Hananantachai · Polrat Wilairatana • \\ Sornchai Looareesuwan · Katsushi Tokunaga
}

Received: 15 January 2007/Accepted: 22 February 2007/Published online: 20 March 2007

(C) The Japan Society of Human Genetics and Springer 2007

\begin{abstract}
Plasmodium falciparum invades erythrocytes via several routes using different red blood cell receptors that include glycophorin A (GYPA) and glycophorin B (GYPB). GYPA has two codominant alleles, i.e., $M$ and $N$, that correspond to the $\mathrm{M}$ and $\mathrm{N}$ antigens, which differ by two amino acids (S1L, G5E); the codominant alleles of $G Y P B$, i.e., $S$ and $s$, correspond to the $\mathrm{S}$ and s antigens, which differ by a single amino acid (T29M). If these antigens influence the efficiency of erythrocyte invasion by malaria parasites, the MNSs phenotype may be associated with the severity of malaria. To examine this, the GYPA and $G Y P B$ genotypes carrying the MNSs antigens were analyzed in 109 and 203 Thai patients with cerebral malaria and mild malaria, respectively. Neither the genotype nor allele frequencies at each locus were statistically different between the cerebral and mild malaria patients. Thus, we conclude that the MNSs antigens do not reveal the difference in susceptibility to cerebral malaria.
\end{abstract}

Keywords Malaria - MNSs antigens - Glycophorin A . Glycophorin B · Thailand

I. Naka $\cdot$ J. Ohashi $(\bowtie) \cdot$ K. Tokunaga

Department of Human Genetics,

Graduate School of Medicine,

The University of Tokyo,

7-3-1 Hongo, Bunkyo-ku,

Tokyo 113-0033, Japan

e-mail: juno-tky@umin.ac.jp

J. Patarapotikul · H. Hananantachai · P. Wilairatana .

S. Looareesuwan

Faculty of Tropical Medicine,

Mahidol University,

Bangkok, Thailand

\section{Introduction}

The malaria parasite Plasmodium falciparum invades human erythrocytes and replicates within them. Erythrocyte invasion by merozoites requires interaction between multiple erythrocyte receptors and their corresponding parasite ligands, such as the $175-\mathrm{kD}$ erythrocyte-binding antigen (EBA-175) of P. falciparum. It has been demonstrated that the glycophorin A (GYPA) expressed on erythrocytes is a receptor of EBA-175 (Adams et al. 1992; Camus and Hadley 1985; Klotz et al. 1992; Orlandi et al. 1992; Pasvol et al. 1982; Sim et al. 1990), and glycophorin B (GYPB) was suggested to be used as an EBA-175 independent $P$. falciparum receptor (Dolan et al. 1994). These observations indicate that GYPA and GYPB play a crucial role in the process of erythrocyte invasion by merozoites.

The GYPA (MIM 111300) and GYPB (MIM 111740) genes, located on chromosome 4 (4q28.2-q13.1), code for antigens responsible for the very common $\mathrm{MN}$ and Ss blood type polymorphisms, respectively. The $\mathrm{M}$ and $\mathrm{N}$ antigens differ by two amino acids (S1L and G5E) and the $\mathrm{S}$ and s by a single amino acid (M29T). These amino acid sites are located in the extracellular domain that may cause differences in receptor-ligand interaction. If a difference exists, the efficiency of invasion by the malaria parasites in individuals with diverse MNSs antigens is expected to vary. Interestingly, GYPA and $G Y P B$ were reported to be fast-evolving genes, with a high rate of nonsynonymous substitutions between humans and other primates. Thus, it has been hypothesized that the human GYPA gene has been evolving rapidly in order to evade malaria parasite invasion (Wang et al. 2003). Further, this hypothesis led us to investigate whether MNSs antigens affect susceptibility to severe malaria. To examine this, we conducted an association study for mild or cerebral malaria in Thai patients. 
The deletion of exon 3 in the GYPC (MIM 110750) gene, GYPCAex3, causing the Gerbich-negative phenotype has been suggested to confer protection against malaria because the GYPCAex3 allele reaches a high frequency in malaria-endemic regions of Papua New Guinea (Booth and McLoughlin 1972; Patel et al. 2001, 2004). In addition, GYPC has been shown to be the receptor for the P. falciparum erythrocyte-binding antigen 140 (Maier et al. 2003). The 27-base-pair deletion in the solute carrier family 4, anion exchanger, member 1 (SLC4A1 [MIM 109270]) gene, SLC4A1 $\triangle 27$, resulting in the Southeast Asian/Melanesian ovalocytosis (SAO), has been reported to be associated with protection from cerebral malaria (Allen et al. 1999; Genton et al. 1995). These observations imply that the GYPCAex3 and SLC4A1 127 alleles influence the association between MNSs antigens and cerebral malaria. Thus, the presence of GYPCAex3 and SLC4A1D27 was also investigated in this study.

\section{Subjects and methods}

Patients with malaria

A total of 312 adult patients with $P$. falciparum malaria (109 cerebral malaria and 203 mild malaria patients) living in northwest Thailand were recruited for this study. All of them underwent treatment at the Hospital for Tropical Diseases of Mahidol University. Clinical manifestations of malaria were as follows. Cerebral malaria was characterized by unrousable coma, positive blood smear for the asexual form of $P$. falciparum, and exclusion of other causes of coma. Mild malaria was characterized by a positive blood smear, fever without other causes of infection, and no manifestation of the following symptoms: high parasitemia ( $>100,000$ parasites $/ \mathrm{ml}$ ), hypoglycemia (glucose $<22 \mathrm{nmol} / \mathrm{l}$ ), severe anemia (hematocrit $<20 \%$ or hemoglobin $<7.0 \mathrm{~g} / \mathrm{dl}$ ), and increased serum creatinine levels $(>3.0 \mathrm{mg} / \mathrm{dl})$. All individuals were 13 years or older, and means of age in the cerebral malaria and mild malaria patients were $28.6 \pm 9.6$ (mean \pm SD) and $25.5 \pm 10.3$ (mean $\pm \mathrm{SD}$ ) years, respectively. This study was approved by the institutional review board of the Faculty of Tropical Medicine, Mahidol University, and the Faculty of Medicine, The University of Tokyo. Written informed consent was obtained from all patients.

\section{Genotyping}

Genomic DNA was extracted from the peripheral blood leukocytes using a QIAamp Blood Kit (Qiagen, Hilden, Germany). The GYPA genotyping was performed by polymerase chain reaction (PCR) direct sequencing.
A 256-bp fragment containing three single nucleotide polymorphisms (SNPs) $(59 \mathrm{C}>\mathrm{T}, 71 \mathrm{G}>\mathrm{A}, 72 \mathrm{G}>\mathrm{T})$ was amplified by PCR using previously reported primer sets (Sasaki et al. 2000), i.e., a $5^{\prime}$ primer GYPA-F (5'-GAGGGAATTTGTCTTTTGCA-3') and $3^{\prime}$ primer GYPA-R (5'-GGTCCCCTAAAATGGGTTA-3'); this fragment determined the $M$ and $N$ alleles. PCR was performed using GeneAmp reagents and AmpliTaq Gold DNA polymerase (Perkin-Elmer Applied Biosystems, Foster City, CA, USA). The amplification process comprised initial denaturation at $96^{\circ} \mathrm{C}$ for $10 \mathrm{~min}$, followed by 40 cycles of denaturation at $96^{\circ} \mathrm{C}$ for $30 \mathrm{~s}$, annealing at $58^{\circ} \mathrm{C}$ for $30 \mathrm{~s}$, and extension at $72^{\circ} \mathrm{C}$ for $30 \mathrm{~s}$ using a GeneAmp PCR system 9700 (Perkin-Elmer Applied Biosystems). The PCR products were subjected to direct sequencing using an $\mathrm{ABI}$ PRISMTM 3100 Genetic Analyzer (Perkin-Elmer Applied Biosystems). The genotyping for $S$ and $s$ alleles of $G Y P B$ (rs7683365) was performed using the TaqMan technology (Assay-on-Demand) on an ABI 7500 system (Applied Biosystems). The genotyping for GYPCAex3 was performed by using previously reported primer sets (Patel et al. 2001). The presence of exons 2 and 3 was examined by a primer set (GPCup 5'-CAGATTCTTGTCCTCTGTTCACAG- $3^{\prime}$ and GPCdn 5'-TCAAAACCACCTCTGAGGGAGAG-3') annealing to conserved sequence around exons 2 and 3 . The amplification process comprised initial denaturation at $96^{\circ} \mathrm{C}$ for $10 \mathrm{~min}$, followed by 40 cycles of denaturation at $96^{\circ} \mathrm{C}$ for $30 \mathrm{~s}$, annealing at $60^{\circ} \mathrm{C}$ for $30 \mathrm{~s}$, and extension at $72^{\circ} \mathrm{C}$ for $30 \mathrm{~s}$ using a GeneAmp PCR system 9700 (Perkin-Elmer Applied Biosystems). The PCR products were subjected to electrophoresis on $10 \%$ acrylamide gel. A 264-bp band (exon 2) is detected in normal/ normal, normal/GYPCAex3, and GYPCAex3/GYPCAex3, and a 240-bp band (exon 3) is detected in only normal/ normal and normal/GYPCAex3. To identify the normal allele, a primer set (GPC349up 5'-GGAAACTGCCGTGACTTCAGA- $3^{\prime}$ and 1,679dn 5'-CATGGTCCTTGCAACAGTTGC-3') was used to amplify a 1,376-bp product. To identify the GYPCAex3 allele and distinguish normal/ GYPCAex3 from normal/normal, a primer set (GPC349up and GPC1680dn 5'-AGGTTAGAATCATACCCCAGG-3') was used to amplify a 1,377-bp product. The amplification process specific for normal or GYPC $\triangle e x 3$ allele comprised initial denaturation at $94^{\circ} \mathrm{C}$ for $60 \mathrm{~s}$, followed by 40 cycles of denaturation at $94^{\circ} \mathrm{C}$ for $30 \mathrm{~s}$, annealing at $60^{\circ} \mathrm{C}$ for $30 \mathrm{~s}$, and extension at $72^{\circ} \mathrm{C}$ for $75 \mathrm{~s}$ using a GeneAmp PCR system 9700 (Perkin-Elmer Applied Biosystems). The PCR products were subjected to electrophoresis on $10 \%$ acrylamide gel. In the genotyping, a Melanesian individual heterozygous for GYPCAex3 was analyzed as a positive control for PCR, together with Thai malaria patients. A PCR for $S L C 4 A 1 \Delta 27$ was performed using a previously reported primer set (Kimura et al. 2003) (5'-GGGCCCA- 
GATGACCCTCTGC-3') and (5'-GCCGAAGGTGATGG CGGGTG-3') spanning the 27-bp deletion. The amplification process comprised initial denaturation at $96^{\circ} \mathrm{C}$ for $10 \mathrm{~min}$, followed by 40 cycles of denaturation at $96^{\circ} \mathrm{C}$ for $30 \mathrm{~s}$, annealing at $60^{\circ} \mathrm{C}$ for $30 \mathrm{~s}$, and extension at $72^{\circ} \mathrm{C}$ for 30 s using a GeneAmp PCR system 9700 (Perkin-Elmer Applied Biosystems). The PCR products were separated on $10 \%$ acrylamide gel to identify the presence of 175 -bp (normal) and 148-bp (SLC4A1 27$)$ fragments.

\section{Statistical analysis}

Fisher's exact test was performed to compare the genotype and allele frequency distributions observed for the cerebral and mild malaria patients. The haplotype frequencies were estimated using the EH program (Xie and Ott 1993) based on the expectation-maximization (EM) algorithm. The differences in the haplotype frequency distribution between the cerebral and mild malaria patients were assessed by a likelihood ratio test. In the EM algorithm for estimating haplotype frequency, the logarithm of the likelihood of the sample $\ln L$ was maximized in each subject group (i.e., $\ln L_{\mathrm{c}}$ for cerebral malaria subjects, $\ln L_{\mathrm{m}}$ for mild malaria subjects, and $\ln L_{\text {all }}$ for both sets of subjects). The likelihood ratio statistic was defined by $\mathrm{LR}=2\left[\ln L_{\mathrm{c}}+\ln L_{\mathrm{m}}-\ln L_{\text {all }}\right]$, which had an approximate chi-square distribution with three degrees of freedom under the null hypothesis of no difference in haplotype frequency distribution. Linkage disequilibrium parameters between GYPA and GYPB alleles, $D^{\prime}$ (Lewontin 1964) and $r^{2}$, were calculated based on the estimated haplotype frequencies for all subjects.

\section{Results and discussion}

The major alleles at the GYPA and GYPB loci observed in the Thai patients were $M$ and $s$, respectively (Table 1). Neither the genotype nor the allele frequencies were significantly different between the cerebral and mild malaria patients (Table 1). In addition, the likelihood-ratio test detected no differences in the estimated haplotype frequency between cerebral and mild malaria patients (Table 2). Although GYPA and GYPB are closely located on human chromosome 4, statistically significant linkage disequilibrium was not observed between them in the Thai population $\left(\left|D^{\prime}\right|\right.$ and $r^{2}$ values for all the subjects were 0.328 and 0.004 , respectively). Neither GYPCAex3 nor $S L C 4 A 1 \triangle 27$ was detected in 24 cerebral and 24 mild malaria patients. Thus, we decided not to analyze the rest of samples and conclude that the presence of GYPCAex3 and SLC4A1 27 does not affect the lack of association of the MNSs antigens with cerebral malaria observed in this study. As these deletions may be associated with protection
Table 1 Genotype and allele frequencies of glycophorin A (GYPA) and glycophorin B $(G Y P B)$ in patients with malaria

\begin{tabular}{llll}
\hline Gene & $\begin{array}{l}\text { Cerebral malaria } \\
(n=109)\end{array}$ & $\begin{array}{l}\text { Mild malaria } \\
(n=203)\end{array}$ & $P$ value* \\
\hline GYPA & & & \\
Genotype & & $118(59.3 \%)$ & 0.351 \\
$M M$ & $58(55.2 \%)$ & $65(32.7 \%)$ & \\
$M N$ & $42(40.0 \%)$ & $16(8.0 \%)$ & \\
$N N$ & $5(4.8 \%)$ & $301(75.6 \%)$ & 0.921 \\
Allele: & & $97(24.4 \%)$ & \\
$M$ & $158(75.2 \%)$ & & 1 \\
$N$ & $52(24.8 \%)$ & $1(0.5 \%)$ & \\
$G Y P B$ & & $36(17.9 \%)$ & \\
Genotype: & & $164(81.6 \%)$ & \\
$S S$ & $1(0.9 \%)$ & $38(9.5 \%)$ & 0.942 \\
$S s$ & $19(17.4 \%)$ & $364(90.5 \%)$ & \\
$s s$ & $89(81.7 \%)$ & &
\end{tabular}

* $P$ values were obtained by Fisher's exact test based on $3 \times 2$ table in genotype frequency comparison and based on $2 \times 2$ table in allele frequency comparison

Table 2 Estimated frequencies of glycophorin A (GYPA) and glycophorin B $(G Y P B)$ haplotypes in patients with malaria

\begin{tabular}{lllc}
\hline Haplotype & $\begin{array}{l}\text { Cerebral } \\
\text { malaria }\end{array}$ & $\begin{array}{l}\text { Mild } \\
\text { malaria }\end{array}$ & $P$ value* \\
\hline$M-S$ & 0.098336 & 0.077834 & 0.830 \\
$M-S$ & 0.654045 & 0.682267 & \\
$N-S$ & 0.001664 & 0.018126 & \\
$N-S$ & 0.245955 & 0.221773 & \\
\hline
\end{tabular}

*P value for the comparison of haplotype frequencies between cerebral and mild malaria groups was obtained by log-likelihood ratio test

Estimated $\left|D^{\prime}\right|$ and $r^{2}$ values for all the subjects were 0.328 and 0.004 , respectively

against malaria infection rather than severe malaria, a further study of malaria-free individuals needs to be conducted in Thailand.

The present results led us to conclude that the MNSs antigens do not reveal a difference in susceptibility to cerebral malaria. The polymorphisms at the following amino acid residues may not influence the receptor-ligand interaction: the 1st and 5th of GYPA (S1L and G5E) and the 29th of GYPB (M29T). Although it has been suggested that the GYPA and GYPB genes undergo positive selection (Wang et al. 2003), the nonsynonymous polymorphisms investigated in this study may not be subjected to selection by $P$. falciparum malaria. 
Acknowledgments The authors sincerely thank the patients who participated in this study. We thank two anonymous reviewers for valuable comments and suggestions. This study was partly supported by the Core University System Exchange Programme under the Japan Society for the Promotion of Science, coordinated by the University of Tokyo and Mahidol University, The National Research Council of Thailand, a Mahidol University grant, and KAKENHI (Grant-in-Aid for Scientific Research) on Priority Areas "Comprehensive Genomics" from the Ministry of Education, Culture, Sports, Science and Technology of Japan.

\section{References}

Adams JH, Sim BK, Dolan SA, Fang X, Kaslow DC, Miller LH (1992) A family of erythrocyte binding proteins of malaria parasites. Proc Natl Acad Sci USA 89:7085-7089

Allen SJ, O'Donnell A, Alexander ND, Mgone CS, Peto TE, Clegg JB, Alpers MP, Weatherall DJ (1999) Prevention of cerebral malaria in children in Papua New Guinea by Southeast Asian ovalocytosis band 3. Am J Trop Med Hyg 60:1056-1060

Booth PB, McLoughlin K (1972) The Gerbich blood group system, especially in Melanesians. Vox Sang 22:73-84

Camus D, Hadley TJ (1985) A Plasmodium falciparum antigen that binds to host erythrocytes and merozoites. Science 230:553-556

Dolan SA, Proctor JL, Alling DW, Okubo Y, Wellems TE, Miller LH (1994) Glycophorin B as an EBA-175 independent Plasmodium falciparum receptor of human erythrocytes. Mol Biochem Parasitol 64:55-63

Genton B, al-Yaman F, Mgone CS, Alexander N, Paniu MM, Alpers MP, Mokela D (1995) Ovalocytosis and cerebral malaria. Nature 378:564-565

Kimura M, Tamam M, Soemantri A, Nakazawa M, Ataka Y, Ohtsuka R, Ishida T (2003) Distribution of a 27-bp deletion in the band 3 gene in South Pacific islanders. J Hum Genet 48:642-645

Klotz FW, Orlandi PA, Reuter G, Cohen SJ, Haynes JD, Schauer R, Howard RJ, Palese P, Miller LH (1992) Binding of Plasmodium falciparum 175-kilodalton erythrocyte binding antigen and invasion of murine erythrocytes requires $\mathrm{N}$-acetylneuraminic acid but not its $O$-acetylated form. Mol Biochem Parasitol 51:49-54

Lewontin RC (1964) The interaction of selection and linkage. I. General considerations; heterotic models. Genetics 120:849-852

Maier AG, Duraisingh MT, Reeder JC, Patel SS, Kazura JW, Zimmerman PA, Cowman AF (2003) Plasmodium falciparum erythrocyte invasion through glycophorin $\mathrm{C}$ and selection for Gerbich negativity in human populations. Nat Med 9:87-92

Orlandi PA, Klotz FW, Haynes JD (1992) A malaria invasion receptor, the 175-kilodalton erythrocyte binding antigen of Plasmodium falciparum recognizes the terminal Neu5Ac(alpha 2-3)Gal-sequences of glycophorin A. J Cell Biol 116:901-909

Pasvol G, Wainscoat JS, Weatherall DJ (1982) Erythrocytes deficiency in glycophorin resist invasion by the malarial parasite Plasmodium falciparum. Nature 297:64-66

Patel SS, Mehlotra RK, Kastens W, Mgone CS, Kazura JW, Zimmerman PA (2001) The association of the glycophorin C exon 3 deletion with ovalocytosis and malaria susceptibility in the Wosera, Papua New Guinea. Blood 98:3489-3491

Patel SS, King CL, Mgone CS, Kazura JW, Zimmerman PA (2004) Glycophorin C (Gerbich antigen blood group) and band 3 polymorphisms in two malaria holoendemic regions of Papua New Guinea. Am J Hematol 75:1-5

Sasaki Y, Nakayashiki N, Saigusa K, Takamiya M, Aoki Y (2000) An application of PCR-single strand conformation polymorphism to MN genotyping. Leg Med (Tokyo) 2:171-174

Sim BK, Orlandi PA, Haynes JD, Klotz FW, Carter JM, Camus D, Zegans ME, Chulay JD (1990) Primary structure of the 175K Plasmodium falciparum erythrocyte binding antigen and identification of a peptide which elicits antibodies that inhibit malaria merozoite invasion. J Cell Biol 111:1877-1884

Wang HY, Tang H, Shen CK, Wu CI (2003) Rapidly evolving genes in human. I. The glycophorins and their possible role in evading malaria parasites Mol Biol Evol 20:1795-1804

Xie X, Ott J (1993) Testing linkage disequilibrium between a disease gene and marker loci. Am J Hum Genet 53:1107 